\title{
Business Process Reengineering for Small and Medium Sized Manufacturing Enterprises
}

\author{
J. McSwiney \\ Business Development Manager, Cascade Designs, Dwyer Road, \\ Midleton, Co. Cork, Ireland. Tel: +353 21 632399, Fax: +35321 \\ 632583
}

\begin{abstract}
This paper examines a range of manufacturing performance programmes. Specific features from each of these programmes that are found in BPR are identified. The differences between a BPR implementation and a WCM implementation for three small and medium manufacturing enterprises are also described in some detail.
\end{abstract}

Keywords

BPR, WCM, SMME, performance improvement

\section{INTRODUCTION}

This paper presents the results of research carried out by the author between January and October 1994. The research was facilitated by both the Computer Integrated Manufacturing Research Unit (CIMRU) and AMT Ireland. The objectives of this research were as follows:

1. To explore, in the context of manufacturing companies, the novelty of Business Process Reengineering (BPR) and preceding performance programmes, in particular World Class Manufacturing (WCM).

2. To explore the relevance of Business Process Reengineering programmes to small and medium sized manufacturing enterprises (SMMEs). 


\section{A VIEW ON BUSINESS PROCESS REENGINEERING}

The first task of the research was to choose a view of Business Process Reengineering. There is no recognised single authority or single view of BPR. In particular, authorities differ along two lines: radical versus incremental change, and the level of information technology (IT) dominance.

In relation to radical versus incremental change issues, both Hammer and Davenport come down on the side of radical change. Hammer et al (1990) emphasise that continuous improvement is not BPR and therefore the simple achievements of continuous improvement is tantamount to failure. They point out that: "Reengineering strives to break away from the old rules...At the heart of business reengineering is the notion of discontinuous thinking - identifying and abandoning the outdated rules that underlie current business operations". Similarly Davenport and Short (1990) are of the view that "Objectives of $5 \%$ or $10 \%$ in all business processes each year must give way to efforts to achieve $50 \%, 100 \%$ or even higher levels in a few key processes...the level of change targeted should be radical". Johansson et al (1993) also accord with the radical view and quote Paul O'Neill, Chairman of ALCOA to support this. "I believe that we have made a major mistake in our advocacy of continuous improvement....Continuous improvement is exactly the right idea if you are the world leader in everything you do. It is a terrible idea if you are lagging...It is probably a disasterous idea if you are far behind. ...we need rapid quantum leap improvements". Childe and Maull (1994) quote an IEEE expert, J. Atkins, as being at the other extreme. Atkins places no requirements on the scale of improvement required. He describes BPR as: "..the current popular term for examining an organisation's business processes and recommending automation or changes to achieve strategic goals".

In relation to the issue of information technology (IT) dominance, all BPR advocates agree on the enabling power of information technology. Hammer (1993) views IT to be “..an essential enabler..”. Similarly Davenport (1993) proposes that: “...information technology should be viewed as a force to fundamentally reshape the way a business is done. ... Business process redesign and information technology are natural partners, yet ... their relationship ... has barely been exploited at all. But the organisations that have used IT to redesign boundary crossing, customer driven processes have benefitted enormously". Gant (1992) sees BPR as simply: "the redesign of processes to take advantage of the enormous potential of information technology". Clearly Gant views IT as both a means and an end. However, not all views are dominated by the IT factor as the above. For example, Touche Ross (1993) provide the following definition of BPR in the promotional literature for their reengineering program facilitation service: "Reengineering: A multidisciplinary approach to implementing fundamental change in the way work is performed across the organisation with the goal of dramatically improving performance and stockholder value". Notice that there is no mention of information technology.

For the purposes of the research associated with this paper the radical improvement attribute of BPR was retained as an essential element. Information technology was considered as both a key element of the reengineered business processes and also as a tool for use during the business process redesign activity. However, IT was viewed strictly as a 
means and not as an end to BPR. It was recognised that valid non-information technology BPR solutions exist.

\section{THE NOVELTY OF BPR}

Hammer and Champy (1993) argue that Business Process Reengineering is fundamentally different from anything that has gone before. "Nor is reengineering the same as ...Total Quality Management...To be sure quality programmes and reengineering share a number of common themes ... However the two programmes also differ fundamentally. ... Fundamentally reengineering is about reversing the industrial revolution. Reengineering rejects the assumptions inherent in Adam Smith's industrial paradigm - the division of labour, economies of scale, hierarchical control and all other appurtenances of an early stage developing economy". At the other extreme Libby (1994) introduces a BPR implementation at Cochrane Furniture in North Carolina as follows: "...came across the book 'The Goal' by Eliyahu M. Goldratt that introduced him to a REENGINEERING approach called SYNCHRONOUS MANUFACTURING. Consistent with TOTAL QUALITY MANAGEMENT thinking synchronous manufacturing is a way to speed material flow through a process using techniques for reducing inventories while improving delivery performance. Cochrane Furniture has achieved genuine LEAN PRODUCTION by establishing a synchronous manufacturing environment". The capitals serve to highlight the variety of improvement programmes referenced.

\begin{tabular}{|l|l|l|}
\hline Decade & Approach & Pioneer or Early Authority \\
\hline $1690(-)$ & Division of Labour & Adam Smith \\
\hline 1890 & Scientific Management & Frederick Taylor \\
\hline 1900 & Mass Production & Henry Ford \\
\hline 1920 & Industrial Engineering & F. Gilbreth \& F. Taylor \\
\hline 1930 & Human Relations Movement & Elton Mayo \\
\hline 1950 & Japanese Quality Revolution & J. M. Juran \& W. E. Demming \\
\hline 1960 & Materials Requirements Planning & William Orlicky \\
\hline 1970 & Manufacturing Resource Planning & Oliver Wright \\
\hline 1970 & Focused Factory & Wickham Skinner \\
\hline 1980 & Total Quality & Philip Crosby \\
\hline 1980 & Just In Time & Taiicho Ohno \\
\hline 1980 & Computer Integrated Manufacturing & \\
\hline 1980 & Optimised Production Technology & Eliyahu Goldratt \\
\hline 1980 & ISO 9000 & NASI \\
\hline 1980 & World Class Manufacturing & Richard Schonberger \\
\hline 1980 & Benchmarking & Rank Xerox \\
\hline 1990 & Lean Manufacturing & Jones \& Roos \\
\hline 1990 & Business Process Reengineering & M. Hammer \& T. Davenport \\
\hline
\end{tabular}

Table 1 Major approaches to manufacturing performance improvement 
The Goal was first published in 1986 , certainly prior to any popular use of the term 'reengineering'. Clearly Libby is of the view that BPR is not new and that it is intimately related to what this paper considers to be previous approaches to manufacturing performance improvement.

The following methodology was used to explore the novelty of BPR.

1. Construct a list of the manufacturing performance improvement programmes or approaches to date.

2. Analyse this list in chronological order comparing and contrasting with previous ideas.

3. Finally analyse Business Process Reengineering, showing clearly how it compares and contrasts with preceding programmes.

A chronological list of what were identified as the major approaches to manufacturing performance improvement are shown in table 1.

The approaches presented in table 2 were found to have pre-empted elements of BPR. The final row (of table 2) identifies the features attributed as being original to BPR.

This research was particularly concerned with the uniqueness of Business Process Reengineering in relation to World Class Manufacturing. It is useful to consider how a BPR implementation would differ from a WCM implementation. The differences can be categorised under the headings of methodology and solution space.

\subsection{Methodology}

A BPR company analysis will usually begin with the customer and then look at entire business processes including the administrative activities. The majority of WCM implementations will focus on the manufacturing function. Administrative functions may or may not be affected. All BPR projects will be initiated from the top down. WCM projects will be initiated by a forum of direct level employees, i.e. from the bottom up. Such projects will centre around the implementation of WCM techniques or will focus on specific manufacturing activities.

\subsection{Solution Space}

BPR embodies a prior expectation that there will be significant restructuring. There is no such prior expectation in a WCM implementation. People will expect the overall departmental structure to remain intact, although reorganisation within the manufacturing department may be anticipated. The significance of this lack of expectation is that if major restructuring is attempted it may meet with huge resistance.

Within BPR radical performance improvement is viewed as an essential outcome. Consider the following axiom of performance measurement: whatever is measured will improve and if it is not measured it will not improve (loosely attributed to Kaplan 1987). The relevance in the current context is that if performance of a change initiative is not measured in terms of radical improvement then the chances of achieving radical improvement are diminished. There is a danger in WCM initiatives that every reasonably 
attractive project identified will be pursued, possibly to the detriment of overall achievement. The BPR approach is to ignore the 'small fry in the hope of a big catch'.

\begin{tabular}{|c|c|}
\hline $\begin{array}{l}\text { Approach to Manufacturing } \\
\text { Performance Improvement }\end{array}$ & $\begin{array}{c}\text { Contribution to } \\
\text { Business Process Reengineering }\end{array}$ \\
\hline Division of Labour & $\begin{array}{l}\text { Recognition of a relationship between structure and performance. } \\
\text { Achievement of radical performance improvement through } \\
\text { restructuring. }\end{array}$ \\
\hline Scientific Management & $\begin{array}{l}\text { Recognition of the possibility of radical performance improvement. } \\
\text { Process analysis and design. }\end{array}$ \\
\hline Mass Production & $\begin{array}{l}\text { A specific case of very effective reengineering of the order } \\
\text { fulfilment business process which was subsequently taken as a } \\
\text { general solution. }\end{array}$ \\
\hline Industrial Engineering & $\begin{array}{l}\text { A hierarchical top down systematic approach to process design. } \\
\text { The professional process redesigner (i.e. the I.E.) }\end{array}$ \\
\hline Manufacturing Resource Planning & $\begin{array}{l}\text { Recognition of information technology as a potential process } \\
\text { improvement enabler. } \\
\text { A programme style implementation as a potential process } \\
\text { improvement enabler. } \\
\text { A programme style implementation methodology, a separate chain } \\
\text { of command for implementation. }\end{array}$ \\
\hline The Focused Factory & $\begin{array}{l}\text { Recognition of the benefit of organisation around a clearly defined } \\
\text { customer focused task (not quite a business process focus). }\end{array}$ \\
\hline $\begin{array}{l}\text { World Class Manufacturing } \\
\text { (includes the ideas associated with } \\
\text { JIT, TQM, Lean Manufacturing } \\
\text { and the human relations } \\
\text { movement) }\end{array}$ & $\begin{array}{l}\text { Cellular manufacturing, i.e. organisation around a product, was a } \\
\text { fully fledged precursor to business process orientation. } \\
\text { People empowerment and the team approach to performance } \\
\text { improvement. } \\
\text { Radical performance improvement through redesign of a stable } \\
\text { manufacturing process. However, radical improvement was not } \\
\text { considered essential for success. }\end{array}$ \\
\hline Business Process Reengineering & $\begin{array}{l}\text { Novelty: } \\
\text { The elevation and total focus on the business process. } \\
\text { The prior expectation that there will be significant restructuring a } \\
\text { "blank state" approach to planning the next state of an existing } \\
\text { system. } \\
\text { Radical performance improvement as an essential requirement, the } \\
\text { exclusion of continuous improvement as a successful outcome. } \\
\text { The elevation, though not origination, of the idea that IT must be } \\
\text { viewed as much more than an automation tool (Pava (1983) and } \\
\text { Browne et al (1988) both emphasised this view). }\end{array}$ \\
\hline
\end{tabular}

Table 2 BPR elements found in manufacturing performance improvement approaches 
Information technology occupies a central role as an enabler of BPR solutions. WCM programmes on the other hand will in some cases be ill-disposed to IT-driven solutions. This attitude is a reaction to the poor impact on overall company performance of many early Manufacturing Resource Planning (MRPII) implementations. These implementations suffered from attempting to automate un-streamlined systems (Browne et al, 1988). World Class Manufacturing arrived on the manufacturing performance improvement programme scene hot on the heels of such misadventures. At one time advocates of WCM saw themselves in opposition to advocates of MRPII. Although such opposition is now mostly in the past, WCM practitioners tend not to jump to IT as an early enabler of performance improvement. It is important to point out that IT solutions have advanced considerably since the days when MRPII was giving IT a bad name.

\section{THE RELEVANCE OF BPR TO SMMES}

BPR is undoubtedly relevant to manufacturing companies. Hammer et al (1993) present overviews of manufacturing related BPR implementations at Hallmark and Kodak. Davenport and Short (1990) see BPR as an application to business processes of approaches pioneered by Industrial Engineers in manufacturing operations. This has given rise to the term white collar Industrial Engineering. However the question of the relevance of BPR to smaller manufacturing organisations is not so clear cut. Very few overt references to BPR implementations in a small company were discovered. Even a cursory analysis of BPR will raise fundamental questions about the relevance of BPR to small companies.

The most effective way to investigate the relevance of BPR to SMMEs would have been to analyse a number of smaller company BPR programme implementations. Such implementations were not available. An alternative approach would have been to create models of existing small or medium sized manufacturing enterprises and to carry out virtual implementations on the models. The weakness with the virtual BPR approach is that at best it would indicate the relevance of the concept of process redesign. It would give no indication of a small company's willingness to undertake the BPR challenge or a small company's ability to carry out a process redesign and implement the outcome. A survey of SMMEs would have been yet another possible way of exploring the relevance of BPR programmes. The problem with such an approach is that BPR is a new and is not yet a widely understood concept. A survey questionnaire or interviewer would both have had to introduce the concept of BPR and obtain useful views on its relevance. This was considered impractical. Faced with this dilemma it was necessary to improvise. The approach taken was to examine a number of World Class Manufacturing implementations. Although WCM and BPR are not the same they do share common principles and similar approaches to implementation. The basic assumption is that an examination of a WCM implementation will give a valid insight into the viability of a potential BPR implementation. The overall methodology employed to test the relevance of BPR to SMMEs is presented as: 
1. Define the concept of a small to medium sized manufacturing enterprise.

2. Formulate a number of hypothesis about the relevance of BPR programmes to SMMEs.

3. Test the hypotheses on three SMMEs using WCM implementations as indicators of potential BPR implementations.

4. Reject or reformulate the hypotheses to reflect the empirical evidence.

The Task force on Small Business Report (1994) defines SMEs (small and medium-sized enterprises) as having less than 250 employees. The Irish Companies Act specifies that the average number of employees of a small company should not exceed 50 . The balance sheet total should not exceed $£ 1.25$ million and turnover should not be in excess of $£ 2.50$ million. The figures for a medium company are 250 employees, $£ 5$ million balance sheet and $£ 10$ million turnover (Doolan 1991). The companies chosen for the research all had less than 100 employees.

Two sets of hypothesis are presented below. The first set are positive in relation to the relevance of Business Process Reengineering programmes to SMMEs. The second set are negative. The hypotheses are derived from Barrier M. (1994), Bannock G. (1981), Barber M. et al (1994), Barber J. et al, (1989), McGee J. (1987), and The Task force on Small Business Report (1994).

\section{Positive}

1. The continued survival or growth of a small or medium size manufacturing enterprise may depend on re-engineering style radical change and performance improvement.

2. SMMEs are capable of implementing fast change and therefore the risk normally associated with a re-engineering programme may be reduced.

\section{Negative}

3. Because of their simple structure SMMEs will not need a 'full blown' BPR programme to exploit lucrative opportunities for restructuring.

4. Managers of SMMEs may not be open to formal improvement programmes.

5. Managers of SMMEs may not be open to the idea of employee empowerment (employee empowerment is an essential element of most BPR solutions).

6. SMMEs may lack the internal expertise to take advantage of BPR style information technology solutions.

7. An SMME may not be able to dedicate sufficient internal resources to achieve successful implementation of a BPR programme.

8. The challenges facing SMMEs may reside mostly in the finance and marketing arenas and therefore may not warrant a business process focus.

9. It is likely, particularly in the area of product development, that an SMME's business process will reside partially outside the organisation. This may have a detrimental impact on the SMME's ability to re-engineer such processes.

The above hypothesis were tested on three case companies each of which are briefly described in table 3. 


\begin{tabular}{|l|l|l|l|l|l|}
\hline $\begin{array}{l}\text { Company } \\
\text { Designation }\end{array}$ & $\begin{array}{l}\text { Number of } \\
\text { Employees }\end{array}$ & $\begin{array}{l}\text { Sales } \\
\text { Turnover } \\
(\mathfrak{f})\end{array}$ & Ownership & $\begin{array}{l}\text { WCM } \\
\text { Initiation }\end{array}$ & BPR Feature \\
\hline Company A & 34 & $\mathrm{n} / \mathrm{a}$ & $\begin{array}{l}\text { United } \\
\text { States }\end{array}$ & $\begin{array}{l}\text { October } \\
1993\end{array}$ & $\begin{array}{l}\text { IT enabled } \\
\text { solution }\end{array}$ \\
\hline Company B & 85 & $£ 6,400,000$ & Irish & $\begin{array}{l}\text { January } \\
1994\end{array}$ & $\begin{array}{l}\text { Major } \\
\text { restructuring }\end{array}$ \\
\hline Company C & 80 & $£ 4,500,000$ & $\begin{array}{l}\text { United } \\
\text { States }\end{array}$ & $\begin{array}{l}\text { March } \\
1994\end{array}$ & $\begin{array}{l}\text { Radical } \\
\text { improvement }\end{array}$ \\
\hline
\end{tabular}

Table 3 Companies used for case studies

Company A specifically requested that no indication of turnover be given, even in a disguised document. All WCM implementations were on-going at the time of the research and had progressed sufficiently to support analysis. The above three companies were selected from a range of alternatives because in each case the WCM programme solution included a particular BPR programme feature. This feature was not to be the sole focus of the analysis, but it was expected to add validity to the findings. The author was actively participating in each implementation. Some personnel in the companies were aware of the research, but it is certain that their behaviour was not affected directly by the research goals. The small sample size may have limited the overall population validity of the research conclusions, i.e. the degree to which it is possible to generalise from the sample observed to the wider population of the same types. However, the participative ethnological style approach ensured particularly strong ecological validity, i.e. the degree to which it is possible to generalise from the context in which the research has taken place to other contexts and settings. In other words, the research was carried out in a natural situation which was very representative of the natural situation about which knowledge was sought.

The following table is a summary of the case study verdicts on each hypothesis. The verdicts were based on analysis of the following aspects of each case:

- The chosen WCM solution.

- The chosen approach to implementation.

- The implementation experience.

The verdicts from each case for each hypothesis were combined to yield a conclusion (see table 4). A conclusion may be to support, oppose or remain inconclusive on the validity of a hypothesis. A conclusion is strong if all results agree. It is weak if one disagrees. It is neither strong nor weak if two results agree and the other is neutral. The conclusion is inconclusive otherwise.

The final step was to reformulate the tested hypotheses into a view on the relevance of BPR to SMMEs. There are potentially many varieties of BPR programmes, even within the restricted view adopted by the research. Similarly there are numerous varieties of SMMEs. Therefore, a simple yes or no answer will not suffice. A qualified answer is presented. The style is emphatic rather than suggestive. 
A Business Process Reengineering programme is relevant to a small or medium sized manufacturing enterprise under the following conditions:

1. The SMME is faced with a situation where survival or growth depends on radical performance improvement or a radical change in the way business is carried out.

2. The SMME commits in advance to dedication of sufficient internal resources to the BPR effort. This is not simply an allocation of personnel. Some of the existing duties of the chosen personnel must be reassigned for the duration of the project.

3. The SMME must be either in control of the major portion of the business process or interest, or they must have the cooperation of the other organisations involved.

4. The BPR effort is facilitated by external BPR experts.

5. Information technology is viewed strictly as a means and not an end. It may potentially be a very powerful enabler, but equally powerful non-IT related BPR solutions may exist.

6. The external BPR experts are able to provide appropriate support for IT solution, design, implementation and maintenance. The maintenance may be contracted elsewhere, but is an essential aspect of a viable IT solution.

7. The implementation pays particular attention to the difficulty of changing inappropriate management styles. Training may not be enough. Visits to other organisations and pilot exercises may be required. Some managers within the SMME may not make the transition.

\begin{tabular}{|l|l|l|l|l|l|}
\hline & Hypothesis & Co. A & Co. B & Co. C & Conclusion \\
\hline 1. & $\begin{array}{l}\text { An SMME may need to undergo radical } \\
\text { change to continue growth. }\end{array}$ & Neutral & Supported & Supported & Supported \\
\hline 2. & $\begin{array}{l}\text { An SMME's ability to achieve fast change } \\
\text { reduces the potential risk of a BPR } \\
\text { implementation. }\end{array}$ & Supported & Opposed & Supported & $\begin{array}{l}\text { Weakly } \\
\text { Supported }\end{array}$ \\
\hline 3. & $\begin{array}{l}\text { SMMEs will not need a formal } \\
\text { improvement programme in identifying } \\
\text { opportunities within their simple } \\
\text { structure. }\end{array}$ & $\begin{array}{l}\text { Opposed } \\
\text { formal improvement programmes in } \\
\text { general. }\end{array}$ & Supported & Opposed & $\begin{array}{l}\text { Weakly } \\
\text { Opposed }\end{array}$ \\
\hline 5. & $\begin{array}{l}\text { Managers of SMMEs may not be open to } \\
\text { employee empowerment. }\end{array}$ & Opposed & Neutral & Supported & Inconclusive \\
\hline 6. & $\begin{array}{l}\text { SMMEs lack the internal expertise to take } \\
\text { advantage of IT solutions. }\end{array}$ & Supported & Supported & Supported & $\begin{array}{l}\text { Strongly } \\
\text { Supported }\end{array}$ \\
\hline 7. & $\begin{array}{l}\text { An SMME may not dedicate sufficient } \\
\text { internal resources to BPR. }\end{array}$ & Neutral & Supported & Supported & Supported \\
\hline 8. & $\begin{array}{l}\text { SMME challenges are in finance and } \\
\text { marketing and therefore do not warrant a } \\
\text { business process focus. }\end{array}$ & Opposed & Opposed & Opposed & $\begin{array}{l}\text { Strongly } \\
\text { Opposed }\end{array}$ \\
\hline 9. & $\begin{array}{l}\text { SMME business processes reside partially } \\
\text { outside the organisation and may be } \\
\text { difficult to reengineer. }\end{array}$ & Supported & Supported & Opposed & $\begin{array}{l}\text { Weakly } \\
\text { Supported }\end{array}$ \\
\hline
\end{tabular}

Table 4 Hypotheses and their conclusions 


\section{REFERENCES}

Bannock, G. (1981) The Economics of Small Business: Return from the Wilderness. Basil Blackwell, Oxford.

Barber, J., Metcalfe, J.S., Porteous, M. (1989) Barriers to Growth: The ACARD Study, in Barriers to Growth in Small Firms (ed. J. Barber et al), Routledge, London.

Barrier, M. (1994) Re-engineering Your Company, Nations Business.

Browne, J., Bradley, P. (1994) The Generic Model of Manufacturing and The Extended Enterprise. Unpublished, CIMRU, UCG, Ireland.

Childe, S.J., Maull, R.S. (1994) Frameworks for Understanding Business Process Re-engineering, Submitted to International Journal of Production Management, Vol 14 No. 12.

Davenport, T.H. (1993) Process Innovation : Re-engineering Work Through Information Technology. Harvard Business School Press, Boston, Massachusetts.

Davenport, T.H., Short, J.E. (1990) The New Industrial Engineering: Information Technology and Business Process Redesign, Sloan Management Review, Summer.

Doolan, B. (1991) Principles of Irish law. Gill and Macmillan, Dublin.

Ford, H. (1926) Mass Production, Encyclopaedia Britannia, 13th Edition, Suppl. Vol2, pp. 821-823.

Gant, J.G., (1992) Work Management: the next step in imaging, Chief Information Officer Journal, Fall, pp. 60-64.

Goldratt, E., Cox, J. (1986) The Goal. Creative Output Books, USA.

Hammer M., Champy, J. (1993), Re-engineering the Corporation : A Manifesto for Business Revolution. Nicholas Brealey, London.

Hammer, M. (1990) Re-engineering Work: Don't Automate, Obliterate, Harvard Business Review, July-August, pp 104 - 112.

Johansson, J.H., McHugh, P., Pendlebury, A.J., Wheeler, W.A. III (1993) Business Process Re-engineering: Breakpoint Strategies for Market Dominance. John Wiley \& Sons, Chichester, West Sussex, England.

Kaplan, R.S., Johnson, H.T. (1987) Relevance Lost: The Rise and Fall of Management Accounting. Harvard Business School Press, Boston, Massachusetts.

Libby, B. (1994) Re-engineering, By the Book, Manufacturing Systems (MFS), Vol 12, Issue 4, April, pp 52-53

Mayo, E. (1933) The Human Problems of an Industrial Civilisation. Macmillan, USA. McGee, J., (1987) Barriers to Growth: The Effects of Market Structure, in Barriers to Growth in Small Firms (ed. J. Barber et al.), Routledge, London.

Mullee, W.B., Porter, D.B. (1963b) Process Chart Procedures, Industrial Engineering Handbook, McGraw-Hill Book Company, Inc., New York.

Pava, C. (1983) Managing New Office Technology: An Organisational Strategy, The Free Press, New York.

Schonberger, R. (1986) World Class Manufacturing: The Lessons of Simplicity Applied. Free Press, New York.

Skinner, W. (1984) The Focused Factory, Harvard Business Review, May-June.

Smith A. (1776) The Wealth of Nations. Glasgow. 
Task force on Small Business (1994) Report, Government Publications, Dublin.

Taylor, F.W. (1911) The Principles of Scientific Management. Harper and Row, New York.

Touche Ross (1993), Re-engineering For Results, TM Management Consultancy

Services Brochure, Touche Ross, London.

Wight, O. (1981) MRP II: Unlocking America's Productivity Potential. CBI Publishing, Boston MA.

\section{BIOGRAPHY}

Joe Mc Swiney graduated from the Cork Regional Technical College in 1986 with a Bachelor of Technology Degree in Electronics Engineering. In that year he joined Concurrent Computers Irl. Ltd., initially as a Manufacturing Engineer and later as Manufacturing Supervisor. In 1989 he joined the CIM Applications Group of AMT Ireland as a Manufacturing Consultant. He spent over five years with AMT Ireland assisting companies improve their manufacturing performance, primarily through the implementation of World Class Manufacturing. In 1994 he completed a two year part time Masters of Business Administration (MBA) degree at University College Galway. In January of 1995 he joined Cascade Designs Ltd. as Business Development Manager. 